\title{
Spigelian hernia: Mesh or not?
}

\author{
Hsieh HF, Chuang $\mathrm{CH}^{1}$, Lin $\mathrm{CH}^{1}$, Yu $\mathrm{JC}^{1}$ and Hsieh $\mathrm{CB}^{1}$ \\ Department of Surgery. Yee-Zen General Hospital. Taoyuan, Taiwan. 'Division of General Surgery. Department of Surgery. \\ Tri-Service General Hospital. National Defense Medical Center. Taipei, Taiwan
}

\section{RESUMEN}

Objetivo: el propósito de este estudio fue comunicar nuestra experiencia en el manejo de la hernia de Spiegel con y sin el empleo de mallas preperitoneales.

Diseño experimental: análisis retrospectivo.

Sujetos: se revisaron las historias clínicas de 11 casos de hernia de Spiegel tratados quirúrgicamente. Se evaluaron las características clínicas, los tratamientos y los resultados clínicos.

Resultados: de los 11 casos que se evaluaron, 7 pacientes se sometieron a reparación abierta de la hernia sin malla extraperitoneal (grupo A) y 4 se sometieron a cirugía abierta con malla extraperitoneal (grupo B). No hubo diferencias significativas en cuanto a edad, sexo, índice de masa corporal, enfermedades de base, síntomas, duración de los síntomas, rasgos del saco herniario o método de abordaje. No se hallaron recurrencias en ninguno de los dos grupos. El periodo medio de seguimiento fue de 8,5 $\pm 3,2$ (años) en el grupo A y de 6,7 $\pm 2,1$ (años) en el grupo B.

Conclusiones: con o sin malla extraperitoneal, la reparación abierta de la hernia de Spiegel consigue buenos resultados.

Palabras clave: Hernia de Spiegel. Hernia. Malla. Laparoscopia.

\begin{abstract}
Objective: the purpose of this study was to report our experience in management and clinical result of Spigelian hernia with preperitoneal mesh repair or without mesh repair.

Experimental design: retrospecitve analysis.

Subjects: the medical records of 11 cases of Spigelian hernia with surgical treatment were reviewed. The clinical characteristic, treatment and clinical result were evaluated.

Results: of the 11 cases that were evaluated, 7 patients underwent open repair of hernia without extra-peritoneal mesh (group A), the other 4 patients underwent open surgery with extra-peritoneal mesh (group B). There were no significant difference in age, gender, body mass index, underlying diseases, symptoms, duration of symptoms, features of hernia sac and method of approach. No recurrence was found in these two groups. The mean follow-up time was $8.5 \pm 3.2$ (years) in group $\mathrm{A}$ and $6.7 \pm$ 2.1 (years) in group B.

Conclusions: whether open repair of spigelian hernia with or without extra-peritoneal mesh gives the same and well result.
\end{abstract}

Key words: Spigelian hernia. Hernia. Mesh. Laparoscopic.

Hsieh HF, Chuang CH, Lin CH, Yu JC, Hsieh CB. Spigelian Hernia: Mesh or not? Rev Esp Enferm Dig 2007; 99: 502-504.

\section{INTRODUCTION}

Spigelian hernia $(\mathrm{SH})$ is a rare condition that first described by Adrian van der Spiegel about the anatomical

Funding acknowledgement: Civilian Administration Division of Tri-Service General Hospital, National Defense Medical Center.

Recibido: 06-12-06.

Aceptado: 13-05-07.

Correspondencia: Chung-Bao Hsieh. Division of General Surgery. TriService General Hospital, 325. Cheng-Kung Road, Sec 2, Neihu 114, Taipei, Taiwan.e-mail: linjh93@yahoo.com.tw boundaries of the abdominal wall area just lateral to the rectus abdominis muscle (1) (Figs. 1-3). The treatment may include open or laparoscopic surgery (2). Laparoscopy is though to be a good technique that offers reduction in hospital stay time, postoperative analgesia, and surgical wound infection $(2,3)$. We reviewed 11 cases of $\mathrm{SH}$, they were all treated with open method, including 7 patients were underwent simple repair of hernia (closure of fascial layers) without extra-peritoneal mesh, the other 4 patients underwent repair of hernia with extra-peritoneal mesh.

The purpose of this study was to evaluate the efficacy of open surgical repair of SH with or without mesh. 


\section{PATIENTS AND METHOD}

From 1985 to 2005,11 patients ( 5 men and 6 women, mean age, 58 years old, range from 43 to 76 years) of $\mathrm{SH}$ were reviewed. The clinical characteristics included age, gender, body mass index (BMI), past history and clinical presentation were recorded. The method of approach, management and mean follow-up time were also were recorded.

\section{Method of approach}

\section{Local}

Patients underwent general anesthesia and a transverse incision over the region of $\mathrm{SH}$ was made. Then dissected the hernia sac and down to the aponeurosis of the external oblique muscle. The hernia sac was opened to check and push the content of sac into the peritoneum then ligation of hernia sac was made. The aponeurosis of external oblique muscle was closed by interrupt suture. This method was completed in 6 cases.

A polypropylene mesh was placed over the extra-peritoneal space and then fixed with interrupt suture. Then the aponeurosis of external oblique muscle was closed. This method was completed in 4 cases. The criteria for mesh repairing depended on surgeons' option. It was often applied in patients with weak aponeurosis or big defects.

\section{Laparotomy}

Patients underwent general anesthesia and a midline abdominal incision. After entering of peritoneum, found out the sac and suture ligation of the defect. This method was completed in one case.

\section{RESULTS}

11 patients were enrolled, including 5 male and 6 female. We reviewed them according to the medical records. The summary data were recorded in table I. Patients without additional extra-peritoneal mesh were labeled as group A; group B was patients with additional extra-peritoneal mesh.

The average age of two groups were $57 \pm 4$ and $60 \pm$ 12.3 years. 3 male and 4 female in group A; 2 male and 2 female in group B. The BMI was compared: $27 \pm 1.2$ in group A; $26.1 \pm 0.9$ in group B. There was one case of chronic obstructive pulmonary disease (COPD) in each group. One patient had been underwent appendectomy in group A. 10 of 11 patients presented with abdominal mass, only one patient was accompanied with abdominal pain. The mean duration of symptoms of the two groups: $3.4 \pm 1.4$ (months) in group A; $3.0 \pm 1.3$ (months) in
Table I. Summary of 11 patients of Spigelian hernia

\begin{tabular}{lccc}
\hline & $\begin{array}{c}\text { Without mesh }(n=7) \\
\text { (Group A) }\end{array}$ & $\begin{array}{c}\text { With mesh }(n=4) \\
\text { (Group B) }\end{array}$ & \\
\hline Age (years) & $57 \pm 4$ & $60 \pm 12.3$ & NS \\
Men/women & $3 / 4$ & $2 / 2$ & \\
BMl (kg/m²) & $27 \pm 1.2$ & $26.1 \pm 0.9$ & NS \\
Past history: & 1 & & \\
COPD & $1 *$ & 0 & \\
$\quad$ Prior surgery & & & \\
Symptoms/sign: & 6 & 4 & \\
Palpable mass & 1 & 0 & \\
Palpable mass with pain & $3.4 \pm 1.4$ & $3.0 \pm 1.3$ & NS \\
Duration of symptoms (months) & 4 & 1 & \\
Ultrasound & 2 & $1 / 3$ & \\
Computed tomography (No.) & $3 / 4$ & $6.6 \pm 3.4$ & \\
Location: (right/left) & $5.7 \pm 2.3$ & & \\
Size of hernia sac (cm) & & $2.1 \pm 0.4$ & \\
Defect of abdominal wall & $1.7 \pm 0.3$ & 4 & NS \\
(mean length, cm) & & 0 & NS \\
Method of approach: & 6 & 0 & \\
Local & 1 & $6.7 \pm 2.1$ & \\
Laparotomy & 0 & &
\end{tabular}

COPD: chronic obstructive pulmonary disease; BMI: body mass index; NS: no significant; " " ": appendectomy.

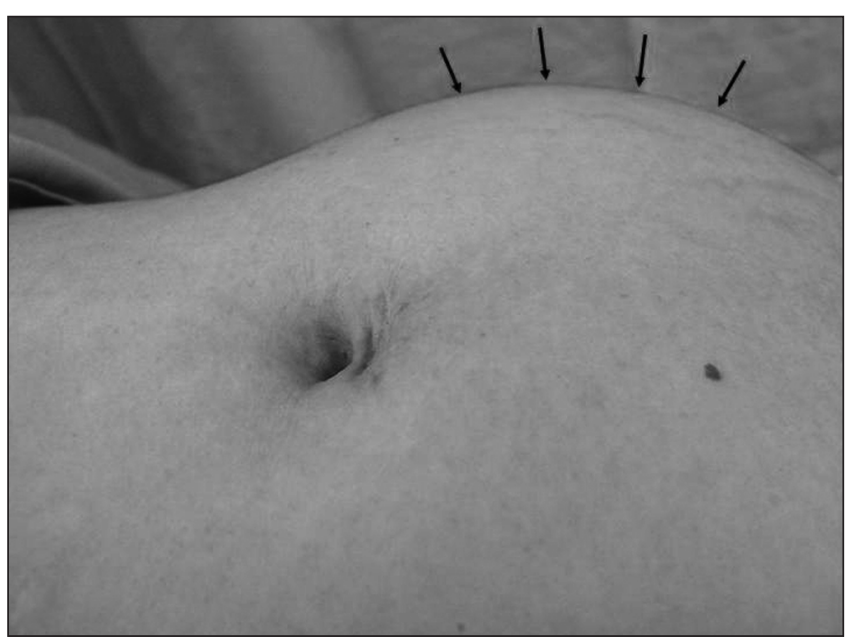

Fig. 1. A 68-year-old female, complaines of reducible palpable mass ovr left lower abdomen for three years. Physical examination demonstrated a mass formation while doing Valsalva (arrow) maneuver.

group B. There were no significant difference between these two groups in age, gender, BMI, underlying diseases, symptoms, and duration of symptoms.

Ultrasound was completed in 4 patients in group A; one patient in group B. CT was completed in 2 patients in group A; 1 patient in group B.

Regarding the features (location, size and abdominal defect) of hernia sac: 3 right side and 4 left side in group $\mathrm{A}, 1$ right side and 3 left side in group $\mathrm{B}$; the mean size of group A is $5.7 \pm 2.3 \mathrm{~cm}$, the group B is $6.6 \pm 3.4 \mathrm{~cm}$; and the mean length of abdominal wall defect in group $\mathrm{A}$ is 


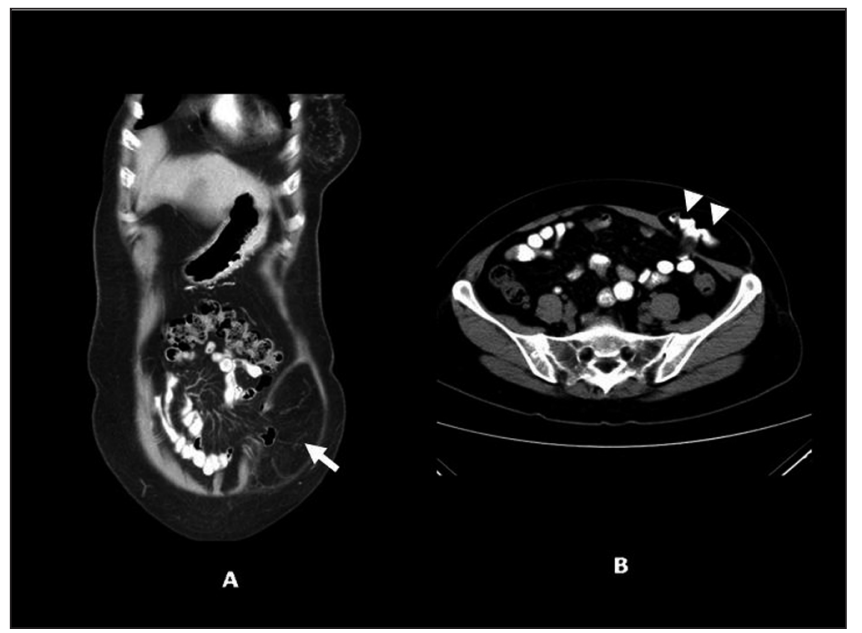

Fig. 2. Computed tomography of abdomen with oral contrast showed a loop of bowel (Fig. 2B, arrow head) and omentum (Fig. 2A, arrow) herniated through the linea similunaris and contained within the external oblique aponeurosis.

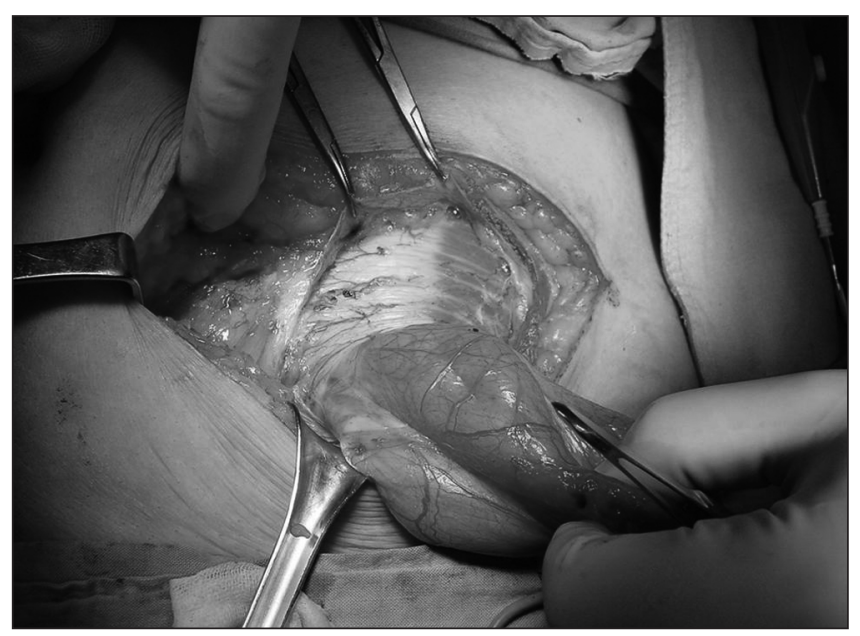

Fig. 3. A local incision was made over the mass. A hernia sac protruded from the union of the aponeurosis of the external oblique, internal oblique and transversus abdominis just lateral to the rectus abdominis muscles.

$1.7 \pm 0.3$, the group B is $2.1 \pm 0.4$. There were no significant difference in the location, size and mean length of abdominal wall of SH.

Most of the patients (10 of 11) underwent method of local approach, one patient underwent laparotomy with repair of SH. No recurrence was found in these two groups. The mean follow-up time was $8.5 \pm 3.2$ (years) in group A and $6.7 \pm 2.1$ (years) in group B.

\section{DISCUSSION}

Spigelian hernia is rare ( 1 to $2 \%$ of all abdominal hernias) (4). The diagnosis is difficult and clinical presentation varies, depending on the contents of the hernia sac (4). In our study, all patients presented with reducible palpable mass, one of them was accompanied with pain. A reducible palpable may be helpful in making the diagnosis of SH. SH almost could be excluded in patients with palpable abdominal mass.

In image diagnostic procedure, Morenilla LM et al. analyzed 162 cases of SH that both ultrasound and CT are helpful diagnostic tools (3). Both ultrasound and CT could give us the detail content of sac.

The surgical treatment of $\mathrm{SH}$ could prevent complication, the recurrence is rare (4). The surgical treatment could be achieved by open method or laparoscopic method. Moreno-Egea A et al. reported the first prospective randomized trial about open and laparoscopic repair of SH (2). He proposed laparoscopic approach as the technique of choice. In our hospital, we routinely used open technique to treat $\mathrm{SH}$. We reviewed our patients and found whether open repair of SH with or without extraperitoneal mesh gave the excellent result. No recurrence was found in these two groups.

In conclusion, although definite diagnosis of $\mathrm{SH}$ is relatively difficult, palpable mass may give us a hint of making diagnosis. We think laparoscopic approach may be a good technique in treatment of $\mathrm{SH}$, but open method may also provide well result if the laparoscopic instrument or technique were not available, especially for patients with recurrence or prior surgery. Repair of SH with or without extra-peritoneal mesh is not a problem. Both of them could give the well result.

\section{REFERENCES}

1. Vos DI, Scheltinga MRM. Incidence and outcome of surgical repair of spigelian hernia. Br J Surg 2004; 91: 640-4.

2. Moreno-Egea A, Carrasco L, Girela E. Open vs. laparoscopic repair of spigelian hernia. Arch Surg 2002; 137: 1266-8.

3. Moles Morenilla L, Docobo Durantez F, Mena Robles J, de Quinta Frutos R. Spigelian hernia in Spain. An analysis of 162 cases. Rev Esp Enferm Dig 2005; 97: 338-47.

4. Spangen L. Spigelian hernia. World J Surg 1989; 13: 573-80. 